SCIENTIFIC LETTER

\title{
Clinicians' preferences for treatments to prevent coronary heart disease: a postal survey
}

\author{
S Bryan, P Gill, S Greenfield, K Gutridge, T Marshall, Birmingham Patient Preferences Group
}

Heart 2005;91:377-378. doi: 10.1136/hrt.2004.035196

$\mathrm{T}$ he decision to offer treatment to prevent coronary heart disease weighs up the benefits of treatment against the disadvantages of treatment. The benefits of treatment are the product of the relative risk of treatment and pretreatment risk. Relative risk is approximately 0.7 for both aspirin and statins. As adverse effects are infrequent, the principal disadvantages of treatment are medicalisation and inconvenience.

Previous research on clinicians' preferences for preventive treatments had a number of weaknesses. Clinicians were asked to decide on their own behalf rather than for their patients. Outcome was expressed only as improvement in mortality, ignoring non-fatal outcomes. Stating only reductions in negative outcomes (loss framing) is likely to increase the uptake of a preventive intervention. ${ }^{1}$ No visual aids were used to illustrate risk, although these improve knowledge and encourage realistic expectations of benefits and harms. There was no test of participants' comprehension of the information provided. This survey investigates the threshold reduction in coronary risk at which cardiologists, general practitioners, and practice nurses would offer treatment to their patients.

\section{METHODS}

A list of physicians with an interest in cardiology was obtained from the West Midlands region of the Royal College of Physicians. A list of practice nurses with an interest in cardiology and a list of general practitioners were obtained from a previous survey. A random sample of one fifth of the 2893 general practitioners, all of the 74 cardiologists, and all of the 154 practice nurses in the sampling frames were posted a questionnaire booklet in 2003. Those who failed to respond received a telephone reminder.

The questionnaire booklet asked participants to indicate whether they would offer drug treatment in six scenarios representing six different levels of pre-treatment five year coronary risk. In each scenario treatment reduced coronary risk by $30 \%$. Participants were informed of the implications of treatment, which were biannual clinic visits and annual blood tests, and also of the prognosis of a coronary eventthree in 10 recover fully, five in 10 survive but are restricted in their usual activities (usually because of chest pain or shortness of breath), and two in 10 die.

For each scenario participants were told the pre-treatment risk, on-treatment risk, and risk reduction with treatment. Risk information was provided in two forms-in words and as decision aids (coloured bar charts). All risks were expressed as frequencies per 100 patients as these are better understood than percentages. $^{2}$ To mitigate framing effects, coronary risk was presented both as the number of persons per 100 who would have a coronary event in the next five years, and the number who would not have a coronary event in the next five years. The numbers were stated twice, indicating the numbers affected by each outcome with and without treatment. Participants were randomly allocated to each of two counterbalanced booklets, one presenting scenarios in descending order of coronary risk, the other in ascending order.

At the end of each booklet, two questions tested participants' comprehension of the numerical risk information. Participants were asked to choose between two otherwise identical treatments that reduced coronary risk by different amounts. Participants who chose the more effective treatment were judged to have understood the numerical information.

Data were entered into SPSS 11.0 and the relationship between thresholds and professional group was investigated by Mann-Whitney $U$ test. Relations between treatment thresholds, the order in which risk scenarios were presented, and participant comprehension were investigated as secondary hypotheses.

\section{RESULTS}

Questionnaires were sent to 775 clinicians. Of these, 70 were confirmed as having retired, died or moved away, and four practice nurses indicated that the questionnaire was not applicable to them. The overall response rate was $42 \%$ (296 of

Table 1 Thresholds at which treatment is recommended by different groups of clinicians

\begin{tabular}{|c|c|c|c|c|c|c|}
\hline \multirow[b]{3}{*}{$\begin{array}{l}\text { Lowest } 5 \text { year coronary risk at which } \\
\text { treatment is recommended* }\end{array}$} & \multicolumn{6}{|c|}{ Number $(\%)$ choosing this threshold } \\
\hline & \multicolumn{3}{|c|}{ Grouped by profession } & \multicolumn{2}{|c|}{ Grouped by comprehension } & \multirow[b]{2}{*}{ All groups } \\
\hline & Cardiologists & $\begin{array}{l}\text { General } \\
\text { practitioners }\end{array}$ & $\begin{array}{l}\text { Practice } \\
\text { nurses }\end{array}$ & Did not understand & Understood & \\
\hline $3 \%$ & $3(7 \%)$ & $29(15 \%)$ & $10(16 \%)$ & $7(29 \%)$ & $35(13 \%)$ & $42(14 \%)$ \\
\hline $6 \%$ & $1(2 \%)$ & $9(5 \%)$ & $10(16 \%)$ & $6(25 \%)$ & $13(5 \%)$ & $20(7 \%)$ \\
\hline $10 \%$ & $14(33 \%)$ & $38(20 \%)$ & $8(13 \%)$ & $1(4 \%)$ & $57(22 \%)$ & $60(20 \%)$ \\
\hline $15 \%$ & $18(42 \%)$ & $60(31 \%)$ & $17(28 \%)$ & $6(25 \%)$ & $85(32 \%)$ & $95(32 \%)$ \\
\hline $20 \%$ & $5(12 \%)$ & $22(11 \%)$ & $7(11 \%)$ & $0(0 \%)$ & $33(13 \%)$ & $34(11 \%)$ \\
\hline $30 \%$ & $2(5 \%)$ & $25(13 \%)$ & $5(8 \%)$ & $3(13 \%)$ & 27 (10\%) & 32 (11\%) \\
\hline Not recommended at $30 \%$ & $0(0 \%)$ & $9(5 \%)$ & $4(7 \%)$ & $1(4 \%)$ & $12(5 \%)$ & $13(4 \%)$ \\
\hline \multirow[t]{2}{*}{ Total } & $43(100 \%)$ & $192(100 \%)$ & $61(100 \%)$ & $24(100 \%)$ & $262(100 \%)$ & $296(100 \%)$ \\
\hline & \multicolumn{3}{|c|}{ Kruskal-Wallis $\mathrm{H}$ test, $\mathrm{p}=0.528$ (NS) } & \multicolumn{3}{|c|}{ Mann-Whitney $U$ test, $p=0.026$} \\
\hline
\end{tabular}

*Approximately equivalent to reductions in 5 year coronary risk of 1\%, 2\%,3\%,4.5\%, $7 \%, 9 \%$ and $>9 \%$, respectively. 
701 ), $60 \%$ (43 of 72 ) cardiologists, 38\% (192 of 505) general practitioners, and $49 \%$ (61 of 124) practice nurses.

Ninety two per cent of clinicians (262/286) answered both comprehension questions correctly. There were differences between professional groups: all cardiologists answered both correctly, $96 \%$ of general practitioners and $73 \%$ of practice nurses $\left(\chi^{2}: p<0.0001\right)$. There was considerable variation in the risk thresholds at which clinicians would offer treatment. Fourteen per cent (42/296) would offer treatment to patients at $3 \%$ five year coronary risk. Four per cent (13/296) of respondents would not offer treatment to patients at even a $30 \%$ five year coronary risk. The median treatment threshold was $15 \%$ five year coronary risk (equivalent to $4.5 \%$ absolute reduction in risk). For all three professional groups, both modal and median thresholds for treatment were 15\% five year risk (equivalent to $4.5 \%$ absolute reduction in risk). Differences in median responses between professional groups were not significant by Kruskal-Wallis $\mathrm{H}$ test (table 1).

Exclusion of respondents who failed to answer both comprehension questions correctly did not affect the median responses. Modal and median treatment thresholds were the same in participants presented with scenarios in descending and ascending order of coronary risk.

The median risk threshold was $6 \%$ for respondents who answered both comprehension questions correctly and 15\% for those who did not (Mann-Whitney U test, two tailed $\mathrm{p}=0.026)$.

\section{DISCUSSION}

Despite low response rates from general practitioners, response rates are comparable to those achieved in a similar postal survey. ${ }^{3}$ Significant numbers of non-specialist clinicians, a quarter of nurses and one in 20 general practitioners, failed to understand the risk information and were more likely to recommend treatment. Our survey may underestimate failures of comprehension as participants who felt they understood the decision aids are more likely to have responded.

Our study concurs with previous studies which concluded that individual clinicians vary widely in the threshold at which they offer treatment. ${ }^{3-5}$ We found similar median coronary risk thresholds to those reported previously. ${ }^{3}$ Our finding of the same median coronary risk threshold across different professional groups differs from previous research and may reflect recent UK treatment guidelines. These guidelines recommend intervention at $30 \% 10$ year coronary risk (equivalent to $15 \%$ five year coronary risk).

In conclusion, there is no consensus among clinicians on a treatment threshold at which to offer preventive treatment. Guidance provided to patients is therefore arbitrary. The extent and implications of poor understanding of risk among clinicians merits further investigation.

\section{Authors' affiliations \\ S Bryan, Health Services Management Centre, University of Birmingham, Birmingham, UK \\ P Gill, S Greenfield, Department of Primary Care and General Practice, University of Birmingham \\ K Gutridge, T Marshall, Department of Public Health \& Epidemiology, University of Birmingham \\ The research was funded by a grant from the Medical Research Council (G0001097). Additional support was provided by the Primary Care Clinical Research and Trials Unit, University of Birmingham. Acknowledgements are due to all the clinicians and other primary care staff who took part in this study, gave their time or made it possible.}

Correspondence to: Dr Tom Marshall, Department of Public Health \& Epidemiology, University of Birmingham, Edgbaston, Birmingham B15 2T, UK; t.p.marshall@bham.ac.uk

Accepted 7 June 2004

\section{REFERENCES}

1 Edwards AGK, Elwyn GJ, Mulley A. Explaining risks: turning numerical data into meaningful pictures BMJ 2002;324:827-30

2 Gigerenzer G, Edwards A. Simple tools for understanding risks: from innumeracy to insight. BMJ 2003;327:741-4.

3 Lewis DK, Barton S. Who decides when to start preventive treatment? A questionnaire survey to compare the views of different population subgroups. $J$ Epidemiol Community Health 2003:57:241-2.

4 Steel $\mathrm{N}$. Thresholds for taking antihypertensive medication in different professional and lay groups: questionnaire survey. BMJ 2000;320:1446-7.

5 McAlister FA, O'Connor AM, Wells G, et al. When should hypertension be treated? The different perspectives of Canadian family physicians and patients. CMAJ 2000;163(4):403-8.

\section{WEB TOP 10}

www.heartjnl.com

These articles scored the most hits on Heart's website during December 2004

1 Investigation and management of chest pain K F Fox

January 2005;91:105-10. (Education in Heart)

2 Catheter ablation for atrial fibrillation

$P$ Jais, P Sanders, L F Hsu, M Hocini, $M$ Haissaguerre January 2005;91:7-9. (Editorial)

3 Theory and practice of defibrillation: (1) Atrial fibrillation and DC conversion

A A J Adgey, $S J$ Walsh

December 2004;90:1493-8. (Education in Heart)

4 Tissue Doppler, strain, and strain rate echocardiography for the assessment of left and right systolic ventricular function

D Pellerin, R Sharma, P Elliott, C Veyrat

November 2003;89(suppl III):iii9-17. (Supplement)

5 Management of hypertension before, during, and after pregnancy

$P R$ James, C Nelson-Piercy

December 2004;90:1499-504. (Education in Heart)

6 Should ablation be the first line treatment for supraventricular arrhythmias?

F G Cosio

January 2005;91:5-6. (Editorial)

7 Clinical assessment of myocardial hibernation

A F L Schinkel, J J Bax, D Poldermans

January 2005;91:111-17. (Education in Heart)

8 Joint British recommendations on prevention of coronary heart disease in clinical practice

December 1998;80:1-29.

9 Management of acute coronary syndromes: an update $K$ A A Fox

June 2004;90:698-706. (Education in Heart)

10 Pathologic assessment of the vulnerable human coronary plaque

$F D$ Kolodgie, $R$ Virmani, A P Burke, A Farb, D K Weber,

$R$ Kutys, A V Finn, $H$ K Gold

December 2004;90:1385-91. (Mini-symposium)

Visit the Heart website for hyperlinks to these articles, by clicking on "Top 10 papers" www.heartinl.com 